\title{
Malignant fibrous histiocytoma presenting as an endobronchial polyp of the carina
}

\author{
N. Shijubo*, F. Sugaya*, A. Imada*, K. Kudoh*, A.Suzuki*, \\ H. Nakata*, M. Satoh**, S. Abe
}

Malignant fibrous histiocytoma presenting as an endobronchial polyp of the carina. $N$. Shijubo, F. Sugaya, A. Imada, K. Kudoh, A. Suzuki, H. Nakata, M. Satoh, S. Abe. (cERS Journals Ltd 1995.

ABSTRACT: A 64 year old man was admitted to hospital due to dyspnoea and stridor.

A peduncular polyp of the carina was found at bronchoscopy. Histological examination of the tumour after resection with endoscopic electronsurgery revealed malignant fibrous histiocytoma (MFH) of myxoid type. With endoscopic neodymiumyttrium aluminium garnet (Nd-YAG) laser surgery, residual tumour was eliminated.

To our knowledge this is the first case with malignant fibrous histiocytoma appearing as a polyp of the carina.

Eur Respir J., 1995, 8, 1430-1431.
*Third Dept of Internal Medicine, and **Dept of Clinical Pathology, Sapporo Medical University School of Medicine, Sapporo, Japan.

Correspondence: N. Shijubo, Third Dept of Internal Medicine, Sapporo Medical University School of Medicine. South-1, West-16, Chuo-ku, Sapporo 060, Japan.

Keywords: Electronsurgery, endobronchial polyp, malignant fibrous histiocytoma, neodymium-yttrium aluminium garnet laser surgery

Received: December 231994

Accepted after revision April 61995
Malignant fibrous histiocytoma (MFH) is a rare tumour in the lower respiratory tract. Only three cases with MFH in the trachea have been published in the medical literature [1-3], and there has been no report on MFH in the main stem bronchi. We describe the first case of MFH presenting as an endobronchial polyp of the carina.

\section{Case report}

A 64 year old Japanese man with a 2 year history of stridor and dyspnoea on exertion was referred to our University hospital in May, 1994. He had never smoked, and had no prior medical history. Physical examination showed decreased respiratory sounds on the right side. Laboratory values were within normal limits. Chest radiography and tracheal tomography disclosed a tumour originating from the carina, with occlusion of the right main stem bronchus. Chest computed tomographic (CT) scan confirmed this finding. Neither enlarged mediastinal lymph nodes nor extrabronchial involvement were observed. Abdominal echogram, abdominal CT scan, and brain CT scan were normal. Gallium scan showed no abnormal accumulation except for the tumour. Arterial oxygen tension $\left(\mathrm{Pa}_{\mathrm{a}} \mathrm{O}_{2}\right)$ was $9.7 \mathrm{kPa}(73 \mathrm{mmHg})$ and arterial carbon dioxide tension $\left(\mathrm{Pa}_{\mathrm{a}} \mathrm{CO}_{2}\right)$ was $4.3 \mathrm{kPa}(33$ $\mathrm{mmHg}$ ). Dynamic spirometry showed an obstructive pattern (vital capacity (VC) 2.8L (83\% predicted); forced expiratory volume in one second (FEV1) $1.5 \mathrm{~L}$ (58\% pred)).

Bronchoscopy revealed a peduncular polyp originating from the carina and moving with respiration (fig. 1). The surface of the polyp was smooth. Biopsy was

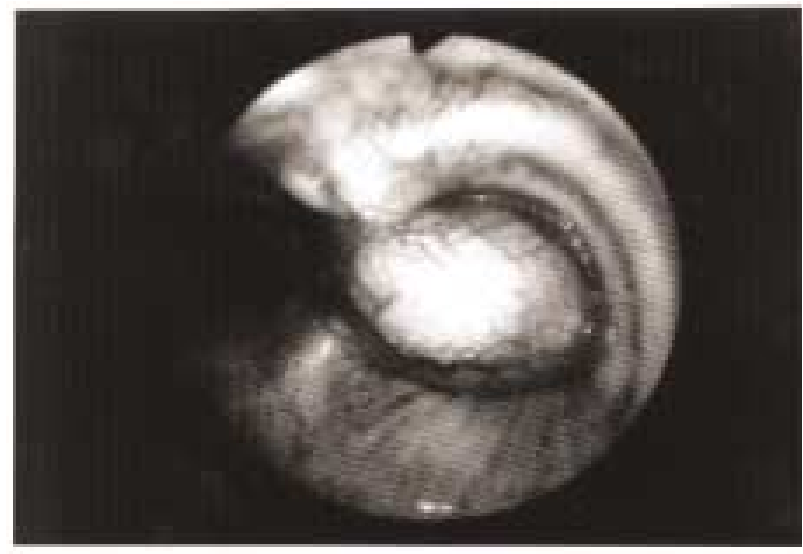

Fig. 1. - Bronchoscopic photograph showing an endobronchial polyp of the carina.

performed endoscopically three times without success. By electronsurgery, endobronchial tumour resection was performed three times. The specimens of the tumour $(25 \times 20 \times 12 \mathrm{~mm} ; 12 \times 10 \times 5 \mathrm{~mm}$; and $10 \times 8 \times 4 \mathrm{~mm})$ were obtained without any complications. For the remaining lesion, neodymium-yttrium aluminium garnet (Nd-YAG) laser treatment was performed weekly, three times. After treatment, no residual tumour was observed. The patient improved and spirometry showed values within normal limits (VC 3.4 L (102\% pred); FEV1 $2.8 \mathrm{~L}$ (80\% pred)). No recurrence was found endoscopically 7 months after Nd-YAG laser treatment. 


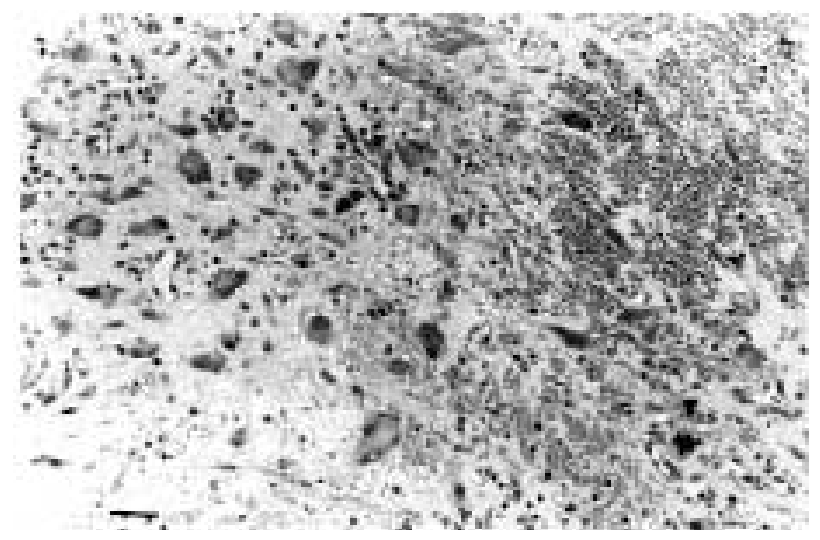

Fig. 2. - Microphotograph of the resected tumour. Proliferation of pleomorphic tumour cells was observed within the myxoid stroma. The arrow indicates an atypical mitosis. (Haematoxylin and eosin staining; internal scale bar is $50 \mu \mathrm{m})$.

Histological examination of the resected polyp demonstrated proliferation of pleomorphic cells and giant cells within the myxoid stroma (fig, 2). Myxoid areas were found in more than $70 \%$ of the resected tumour. The tumour cells were immunohistiochemically positive for $\alpha_{1}$-antitrypsin and vimentin, but negative for S100 protein, smooth muscle actin and factor VIII related antigen. The diagnosis of myxoid type MFH was confirmed [6].

\section{Discussion}

Primary tumours of the trachea and carina are uncommon. It has been reported that squamous cell and adenoid cystic carcinoma are the most frequently encountered primary tumours of the trachea and carina $[4,5]$. These malignant tumours can be diagnosed by routine endoscopic forceps biopsy. In the present case, electronsurgical resection was necessary to obtain the diagnosis of MFH.

MFH usually presents as a deep, soft-tissue sarcoma occurring in adults between the fifth and seventh decades of life. In the present case, we were unable to find any tumour outside the central airways. Intrathoracic $\mathrm{MFH}$ is rare $[1-3,7,8]$, although MFH may occur in virtually any site of the body, including visceral organs. Only three cases with MFH of the trachea have been published in the literature [1-3]. To our knowledge, this is the first report on $\mathrm{MFH}$ presenting as an endobronchial polyp of the carina.

Primary neoplasms of the trachea and carina should be surgically resected, since these patients can be expected to have long survival after complete resection in the absence of distant metastasis [4, 5]. However, MANSOUR et al. [5] reported $8 \%$ operative mortality in 45 tracheal resections from 1974 to 1993 . In their neoplastic group, there was an operative mortality rate of $20 \%$. In the present case, carinal resection with bilateral bronchotracheal anastomoses should have been required, a procedure which would be associated with a higher risk than tracheal resection and primary anastomosis. After information about therapeutic alternatives, the patient preferred endoscopic treatment.

Nd-YAG laser treatment through fibreoptic bronchoscopy has been shown to be of value for unresectable neoplasms occluding central airways [9]. Since myxoid type MFH is much less aggressive, although more prone to local recurrence, than the common type of MFH [10], Nd-YAG laser treatment was chosen for the residual lesion of the reported case.

\section{References}

1. Louie S, Cross CE, Amott TR, Cardiff R Postirradiation malignant fibrous histiocytoma of the trachea. Am Rev Respir Dis 1987; 135: 761-762.

2. Randleman CD, Unger ER, Mansour KA. Malignant fibrous histiocytoma of the trachea. Ann Thorac Surg 1990; 50: 458-459.

3. Wang YH, Wang JL, Lin AS, Cheng L. Malignant fibrous histiocytoma of the trachea combined with thymic carcinoma. Chang Keng I Hsueh 1993; 16: 271-274.

4. Person FAG, Todd TR, Cooper JD. Experience with primary neoplasmas of the trachea and carina. J Thorac Cardiovasc Surg 1984; 88: 511-518.

5. Mansour KA, Lee RB, Miller Jr JL. Tracheal resections: lessons learned. Ann Thorac Surg 1994; 57: $1120-1125$.

6. Du Boulay CEH. Demonstration of alpha ${ }_{1}$-antitrypsin and alpha $_{1}$ - antichymotrypsin in fibrous histiocytoma using the immunoperoxidase technique. Am J Surg Pathol 1982; 6: 559-564.

7. Kern WH, Hughes RK, Meyers BW, Harley DP. Malignant fibrous histiocytoma of the lung. Cancer 1979; 44: 1793-1801.

8. Lee JT, Shelburne JD, Linder J. Primary malignant fibrous histiocytoma of the lung: a clinicopathologic and ultrastructural study of five cases. Cancer 1984; 53: $1124-1130$.

9. Oho K, Ogawa I, Amemiya R, et al. Endoscopic NdYAG laser surgery in the trachea and bronchus. Endoscopy 1983;5: 302-306.

10. Weiss SW, Enzinger FM. Myxoid variant of malignant fibrous histiocytoma. Cancer 1977; 39: 1672-1685. 